Int. J. Dev. Biol. 53: 1549-1556 (2009)

doi: $10.1387 / \mathrm{ijdb} .072308 \mathrm{bg}$

\title{
Epithelial resealing
}

\author{
BEATRIZ GARCIA-FERNANDEZ, ISABEL CAMPOS, JENNIFER GEIGER, ANA C. SANTOS \\ and ANTONIO JACINTO* \\ Instituto de Medicina Molecular, Faculdade de Medicina da Universidade de Lisboa, Lisboa, Portugal
}

\begin{abstract}
Epithelia have the essential role of acting as a barrier which protects living organisms and its organs from the surrounding milieu. Therefore, it is crucial for epithelial tissues to have robust ways of maintaining its integrity despite the frequent damage caused by injury, inflammation and normal cell turnover. All epithelia have some capacity to repair themselves. However, the wound-healing process differs dramatically between the developmental stage and the type of tissue involved. In this review, we will not analyse all aspects of wound healing; instead we will focus on the capacity which several simple epithelial tissues have to reseal small discontinuities very rapidly and efficiently, a process that we call epithelial resealing. We will start by describing the initial experiments which demonstrated the existence of a purse string mechanism to repair embryonic wounds and we will compare this mechanism with embryonic morphogenetic movements which resolve epithelial discontinuities that arise during the normal course of development. We will then discuss other contexts in which epithelia resealing occurs, both in cell culture systems and in adult tissues, and which suggest that at least some of the mechanisms that regulate epithelial resealing may be conserved, acting in several types of simple epithelia, both in embryos and in adults, and across species.
\end{abstract}

KEY WORDS: wound healing, tissue repair, actomyosin cable, filopodia, lamellipodia

\section{Embryonic wound healing}

The process of embryonic purse string wound healing was initially described in the chick embryo by Martin and Lewis (1992). Fluorescently tagged phalloidin used to visualize the distribution of filamentous actin, revealed a thick cable of actin in the basal epidermis at the leading edge of the marginal cells surrounding the wound (Martin and Lewis, 1992). It was then put forward that the contraction of such a cable would provide the force necessary to draw the wound edges together to achieve re-epithelialisation. Consistent with this hypothesis, when de novo assembly of filamentous actin is prevented by the addition of cytochalasin D, embryonic mouse wounds completely fail to re-epithelialise (McCluskey et al., 1993; McCluskey and Martin, 1995). A few years later, it was shown that in chick embryos another component of the contractile apparatus, the motor protein Myosin II, was assembled in a co-ordinated manner in the leading edge of the wound margin cells, together with cadherins, that enable the intracellular cable to link via adherens junctions with neighbouring cells (Brock et al., 1996). Excisional wounds in the animal cap of early embryos of the frog Xenopus laevis seem to heal in a very similar way. These wounds close via three distinct processes: the assembly of an actomyosin purse string in the epithelial cells at the wound margin, the contraction and ingression of exposed deep cells, and the protrusive activity of epithelial cells at the margin (Davidson et al., 2002).

Although most of the initial studies on embryonic wound healing were done in vertebrate organisms such as mouse, chick and Xenopus, the fundamental molecular mechanisms of embryonic wound healing appear to be conserved across species (Martin and Lewis, 1992; McCluskey et al., 1993; Brock et al., 1996; Davidson et al., 2002; Wood et al., 2002). The first detailed studies of insect wound healing were reported by Wigglesworth (1937) using Rhodnius, but it was only in recent years that Drosophilabecome a key model system to unravel the molecular mechanisms of epithelial repair. Advances in live imaging of Drosophila embryos expressing GFP-fusion proteins made possible time lapse microscopy of the normal wound healing process, allowing the exact sequence of cell shape changes and tissue movements to be determined (Wood et al., 2002). The same authors found that epithelial resealing in small embryonic Drosophila wounds was achieved entirely by cell shape changes and

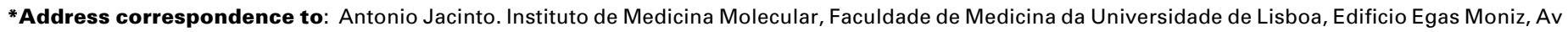
Prof Egas Moniz, 1649-028 Lisboa, Portugal. Fax: + 351-21-799-9504. e-mail: ajacinto@fm.ul.pt web: www.imm.ul.pt
}

Final author-corrected PDF published online: 6 November 2008. 
rearrangements, and did not seem to rely on cell division. They observed that the leading edge cells at the wound margin increasingly constricted their apical edges and elongated as the wound drew closed. Occasionally, cells withdrew completely from the wound margin and become accommodated at rear positions thus decreasing the number of cells at the marginal row. The polarized constriction and marked elongation of the wound marginal cells was again attributed to the contraction of an actomyosin cable that assembles at the leading edge of the cells just minutes after wounding and is linked intercellulary through adherens junctions (Wood et al., 2002) (see Fig. 1A).

Through real time imaging of the wound healing process, Wood et al. (2002) made an additional and crucial observation: at final stages of wound closure opposing leading edge cells make contact through actin based cell protrusions such as filopodia and lamellipodia. These structures are important in the final knitting together of opposing epithelial sheets by allowing tugging of neighbouring cells on one another (see Fig. 1 B,C). Filopodia and lamellipodia protrusions in the context of purse string epithelial resealing were for a long time disregarded probably due to the fact that these morphological features are not always preserved during fixation protocols. However, they are now thought to be essential for the correct matching and adhesion of opposing epithelial cells during wound healing (Wood et al., 2002).

The fact that the actomyosin cable in the leading edge cells is assembled just minutes after wounding (Martin and Lewis, 1992; McCluskey and Martin, 1995; Wood et al., 2002), implies that at least the initial cable formation relies on rapid re-deployment of existing actin. Rapid re-organisation of cytoskeleton structures occurring in other cellular environments is mediated by the Rho family of small GTPases including Rho, Rac and Cdc42 (for a review see Tapon and Hall, 1997). More specifically, Rho is necessary for the assembly of actin stress fibres and associated focal adhesion complexes in serum-starved fibroblast, Rac was shown to be required for the rapid polymerisation of actin at the plasma membrane to form lamellipodia, and Cdc42 was shown to mediate the rapid extension of filopodia (Ridley and Hall, 1992; Ridley et al., 1992, Nobes and Hall, 1995). It was therefore not surprising to see that small GTPases are mediators in the assembly of the actin cable, the contraction of which drives wound closure. Brock et al. (1996) showed that treating the wound edge cells with a Rho-inhibitor, but not with a Rac-inhibitor, blocks both the actin cable assembly and the subsequent wound closure movements in chick embryonic wounds. Likewise, laser wounds in triple mutants of the three DrosophilaRac genes, Drac1, Drac2 and $\mathrm{Mt}$, showed no significant retardation in wound closure (Wood et al., 2002). Also consistent with the chick model, embryonic wounds in Rho1 Drosophila mutant embryos, fail to assemble a continuous actin cable in wound-edge cells (Wood et al., 2002). However, these cells extend three times more filopodia than their wild-type counterparts and, although less efficiently, Rho1 mutant embryos still manage to close small wounds by localized tugging and zipping. On the other hand, small wounds induced on dominant-negative Cdc42-expressing epidermis, were able to assemble an actin cable in leading edge cells but failed to extend any filopodia or lamellipodia protrusions, which prevented them from totally sealing, leaving open a tiny hole that was not fully repaired (Wood et al., 2002).

\section{Epithelial morphogenesis during development}

Some of the morphogenetic movements that occur during embryogenesis, such as Drosophila dorsal closure (Fig. 2A) and C. elegansventral enclosure, have striking similarities with wound healing and have emerged as powerful models to study epithelial resealing. Dorsal closure is a process whereby a series of tissue movements, in the absence of cell division, reseal the dorsal epithelial discontinuity exposed in previous phases of embryogenesis. During dorsal closure, two fronts of the dorsal epidermis elongate along the dorsal/ventral (D/V) axis and move towards each other to seal the dorsal region of the embryo, which is initially covered by a transient tissue called the amnioserosa (reviewed in Martinez-Arias, 1993).

As seen in epithelial wound healing, an actomyosin cable plays a crucial role in driving dorsal closure tissue movements. The leading edge of the dorsal-most epidermal cells accumulate Factin (Fig. 2B) and Myosin II (Fig. 2C) to assemble a cable that contracts as a purse string, coordinating the dorsal migration of the epithelial fronts and contributing to the closure of the dorsal "hole" (Young et al., 1993; Franke et al., 2005). Microsurgery of the actomyosin cable using laser ablation together with biophysical modelling have demonstrated the importance of actomyosin contractibility in the process of dorsal closure and provided a significant contribution to the understanding of how tissue forces translate into complex morphogenetic movements (Kiehart et al., 2000; Hutson et al., 2003; Peralta et al., 2007). As the epidermis moves dorsally, the amnioserosa contracts to help pull the lateral epithelial cells toward the dorsal midline. At the end of the process, the epidermal cells meet and connect to each other starting at the anterior and posterior ends of the "hole", and
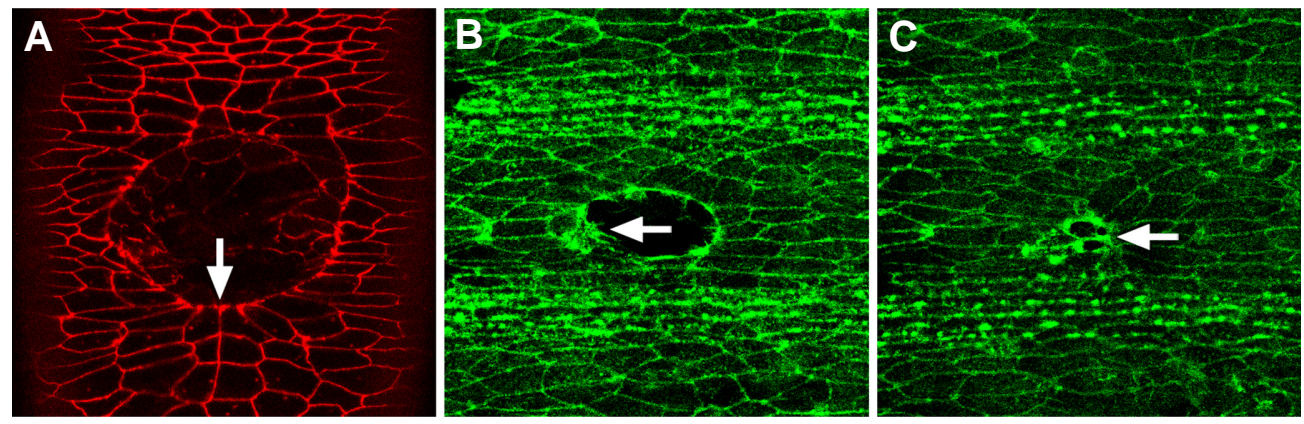

Fig. 1. Wound healing in Drosophila embryos. (A) Upon induction of a small wound, the cells at the margin of the wound accumulate E-Cadherin, which contributes to make specialized junctions with each other at their leading edge (arrow). E-Cadherin distribution is detected using E-Cadherin-GFP (artificiality coloured red in this panel). (B) An actomyosin cable assembles around the wound hole. The cells at the margin of the wound express filopodia and lamellipodia at their leading edge (arrow). The actin filaments are marked using a Moesin-GFP transgenic construct. (C) In the final phases of closure the cytoskeletal protrusions reach each other and help to knit the opposing epithelial fronts together (arrow). 

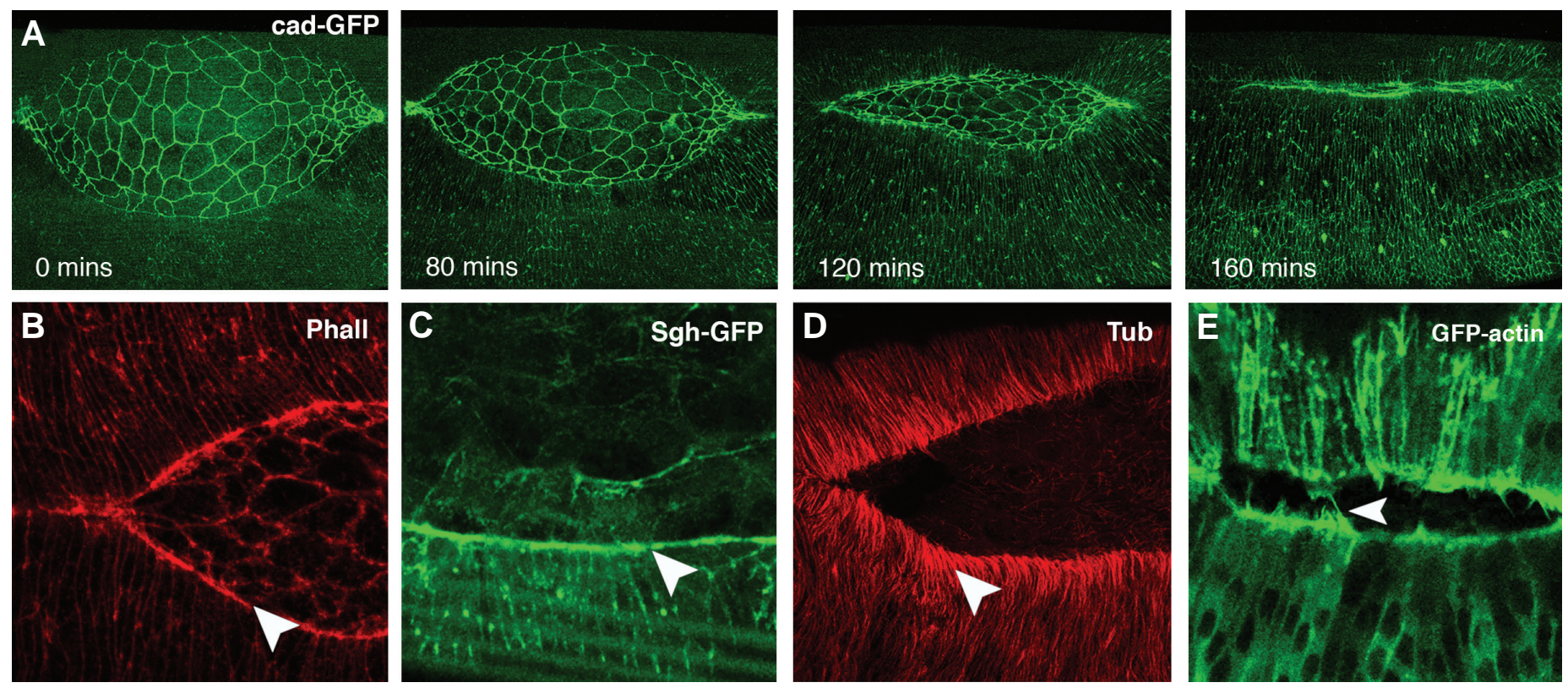

Fig. 2. Epithelial resealing during development - dorsal closure. (A) Time-lapse confocal series of Drosophila embryo during dorsal closure. ECadherin-GFP reveals the cell-cell junctions and outlines the amnioserosa and the epidermal cells. During dorsal closure, the epithelial fronts move forward and zip up at the dorsal midline covering the region that was initially occupied by the amnioserosa. (B-E) Higher magnification of the leading edge cells during dorsal closure showing key features of this epithelial resealing process. (B) Phalloidin staining highlights the accumulation of F-actin in the actomyosin cable (arrowhead). (C) Spaghetti-squash-GFP shows the subcellular localization of the Myosin II regulatory light chain in the actomyosin cable (arrowhead). (D) $\beta$-Tubulin staining showing that the microtubule orient perpendicular to the leading edge and are enriched in the leading edge cells (arrowhead). (E) GFP-actin at the very late stages highlights the actin protrusions establishing the contact between the opposing epithelial fronts (arrowhead).

zipping up the dorsal epidermis towards the middle to completely reseal it (reviewed in Jacinto et al., 2002). The zipping occurs with the help of cytoskeleton protrusions produced by the leading edge cells; lamellipodia and filopodia (Fig. 2E) from opposing epithelial fronts interdigitate to initiate the formation of new adhesions that reseal the dorsal epidermis (Harden et al., 1996; Jacinto et al., 2000). In order to set up the actomyosin cable and produce protrusions in their dorsal most interface, the leading edge cells have to be organised in a polarised manner. These cells exhibit a unique distribution of proteins involved in the establishment of planar cell polarity and make specialized adhesions with the amnioserosa, excluding at this interface proteins that are normally associated with adherens and septate junctions (Kaltschmidt et al., 2002; Kaltschmidt and Martinez Arias, 2002). Interestingly, prior to the polarisation of the leading edge cells, the microtubules reorganise in dorsoventral apical bundles (Fig. 2D) suggesting that they are involved in the regulation of the events at the leading edge, possibly transporting essential factors to that region of the cells (Kaltschmidt et al., 2002; Jankovics and Brunner, 2006). Similar to embryonic wound repair, the control of cytoskeleton structures during dorsal closure is primarily mediated by the small GTPases Rho, Rac and Cdc42 (reviewed in Harden, 2002; Jacinto et al., 2002).

In the epithelial resealing process the lamellipodial and filopodial protrusions provide the initial contacts for connecting leading edge cells, but how do these contacts develop into mature junctions? This process may rely on the clustering of adhesion proteins at the tips of the protrusions, as it has been described in ventral enclosure in C. elegans. Raich et al. (1999) proposed an essential role for filopodia in the formation of rapid intercellular adhesion contacts, the 'filopodia priming' model. According to this model, opposing epithelial cells extend filopodia protrusions containing organized bundles of actin filaments and high levels of cytoplasmic $\alpha$-Catenin, that is rapidly recruited to the site of nascent junctions. It is only in the presence of Cadherin that $\alpha$ Catenin is stabilized at these sites, and the authors suggest that Cadherin-Catenin complexes presumably formed provide a mechanism for the rapid creation of nascent junctions that precede the formation of mature adherens junctions (Raich et al., 1999). Additional evidence that stable adherens structures stem from filopodia and lamellipodia contacts, came from the work of Vasioukhin et al. (2000) in cultured mouse skin keratinocytes.

\section{Tissue repair in vitro}

In vitrostudies using epithelial monolayer cultures have shown to be very useful in the dissection of the mechanisms and molecules involved in wound re- epithelialisation, as the system allows for easy experimental manipulation including the use of specific inhibitors at precise time points. These studies are also a good way of testing, in mammalian systems, the genes and pathways unravelled in genetic systems such as the fly.

Several of these in vitro studies have shown that there are two efficient ways of repairing an epithelial wound. One is the coordinated purse string contraction of an actomyosin ring, the other is a lamellipodia-dependent cell migration to the wound site. Large wounds or wounds where cell-cell contacts were disrupted seem to heal relying on lamellipodia-dependent cell migration to the 
wounded area, while smaller wounds (less than 8 cell diameters), in which the epithelial structure is maintained, depend on the contraction of an actomyosin cable that transmits contraction forces to the epithelium through adherens junctions (Bement et al., 1993).

Russo etal. (2005) very nicely describe how small oligocellular wounds inflicted on human intestinal epithelial cells (Caco-2) in culture heal in two phases. A first phase of Rho kinase dependent actomyosin ring assembly and a second phase of Myosin Light Chain Kinase (MLCK) dependent wound contraction. The concerted action of these two kinases, Rho kinase and MLCK, control respectively the formation of an actomyosin ring and its purse string contraction, apparently without the help of any other actin based structure, such as filopodia or lamellipodia, and seem to be a very efficient way of closing a small wound.

Interestingly, different cell types seem to use slightly different healing strategies. Tamada et al. (2007) show that in MDCK cells Rho kinase is required for the formation of an apical actomyosin ring around the wounded area and consequently for cell shape changes. However, these authors found little or no effect of MLCK in wound closure, in contrast to what was described by Russo et al. (2005) for Caco-2 cells. Healing in MDCK cells also seems to rely on the extension of basal membrane protrusions, mainly lamellipodia, towards the wound site, something that was never observed in the Caco- 2 cell study. These inconsistencies raise the question of whether different organisms/organs rely on different mechanisms of wound healing or whether alternative wounding methods may account for the variations observed.

An apparently different phenomenon that also relies on the formation and contraction of an actomyosin cable is apoptotic cell extrusion in healthy epithelia. Using MDCK cells cultures, Rosenblatt et al. (2001) showed how Rho GTPase-dependent actomyosin cable contraction in the cells that surround an apoptotic cell allows for the extrusion of this cell without challenging the epithelia integrity. These authors saw that both adherens and tight junctions were maintained between the apoptotic cell and their neighbours during the entire extrusion in order to maintain the integrity of the tissue. The authors further showed that even when large portions of apoptotic cells are being extruded from the MDCK epithelia, barrier function (measured by the electrical resistance of the MDCK monolayer) is kept because the remaining live cells seem to be able to stretch as much as 2 cell diameters to cover the space previously occupied by the dying cells.

Another example of epithelial cell extrusion that relies on an actomyosin cable is the abdominal replacement of larval epidermal cells by histoblasts during Drosophila metamorphosis. Recently, Ninov et al. (2007) showed that this massive cell replacement is dependent on the apical actomyosin contraction of larval epidermal cells. The apical constriction of these cells is both necessary and sufficient for their delamination and plays a crucial role in bringing histoblasts together. Not surprisingly, Rho kinase activity modulates the ring contraction of these cells (Ninov et al., 2007), showing once more the conservation of mechanisms between flies and mammals.

\section{Epithelial resealing in adults}

Although the actin purse string mechanism for wound closure was initially described as an embryonic phenomenon (Martin,
1997) a body of evidence has accumulated in recent years, suggesting that this type of mechanism is also used in a variety of adult tissues and organisms to repair small epithelial discontinuities. One such tissue is the intestinal epithelium, which undergoes a high level of cellular turnover. In the mouse, for example, approximately 1400 cells are shed from each villus/day (Potten and Loeffler, 1990). Each time a cell leaves the epithelium and dies by apoptosis, it leaves behind a hole in the epithelium that must be resealed through a mechanism that is normally called restitution. Watson and colleagues estimate that in mouse models, $3 \%$ of the cell positions in the intestinal epithelia are actually gaps, which are presumably left behind after apoptotic cell extrusion and range in size from the diameter of a cell down to various smaller sizes (Watson etal., 2005). Live imaging demonstrated that these gaps take 60 minutes to close (Watson et al., 2005). Amazingly, the intestine is able to maintain a constant permeability barrier in spite of this large amount of cell loss, therefore an efficient and rapid process of hole closure must be in place to continually restore epithelial integrity to this tissue.

Histological studies of human colonic tissue have revealed a concentration of Myosin, in its activated phosphorylated form, along the lateral sides of cells neighbouring a hole in the epithelium left by an extruding cell (Russo et al., 2005; Bullen et al., 2006). In addition to this, ZO-1, a component of tight junctions was shown to accumulate at the apical membrane of neighbouring cells in both human (Bullen etal., 2006) and mouse (Watson etal., 2005). In some cases, cellular extensions of neighbouring cells were also observed reaching into the gap. Taken together, this suggests that a tight-junction anchored actomyosin contractile cable, analogous to that seen in embryonic and tissue culture models (as described above) is also at work in these cells. In some cases ( $9 \%$ of fixed mouse tissue (Watson et al., 2005), $2 \%$ fixed human tissue (Bullen et al., 2006)) ZO-1 is observed at the base of a shedding cell where bordering cells meet in a V-shape, which is contrary to the established idea of apical purse string sealing, but consistent with recent observations in cultured MDCK monolayers, showing that ZO-1 can localize both apically and basally in cells bordering a small wound (Tamada etal., 2007). This tissue culture study also described the presence of lamellipodia at the basal lateral surfaces of wound-bordering cells, agreeing with the observations in live mouse tissue that in $45 \%$ of the cases, lamellipodia from neighbouring cells contacted each other basally under the gap left by a shedding cell (Watson et al., 2005).

The actin purse string mechanism for wound closure does not fully explain the efficient maintenance of the intestinal permeability barrier considering the amount of gaps present. Watson et al. (2005) describe a reflective "impermeable substance" that effectively plugs temporarily the basal half of the gaps and remains until gaps are closed. They postulate that this is extra cellular material, possibly heparin sulphate, secreted by neighbouring cells, although this idea remains to be explored. This is similar to what is seen in adult skin wounds where a fibrin clot is formed to rapidly plug the hole as a first line of defence (reviewed in Singer and Clark, 1999).

Tissue repair in the stratified corneal epithelium is also dependent on a purse string mechanism. Danjo and Gipson (1998) determined that when a small wound $(2 \mathrm{~mm})$ is inflicted on the cornea of living mice, an actin filament cable forms within 3 to 6 hours and is present until wound closure (approximately 24 hours; 
Danjo and Gipson, 1998). This cable is only present in the leading edge cells, which in addition extend lamellipodia into the wound gap. These authors also show that adherens junctions and not tight junctions are responsible for anchoring the actin cable. By performing double immuno-labelings with phalloidin and various junction components, they found that $\alpha$ and $\beta$-Catenin concentrate at actin cable "insertion points", while E-Cadherin and $\gamma$ Catenin co-localize at these points, but more evenly distribute along the lateral membranes of the leading edge cells. The final proof that these cable anchor points are adherens junctions and not tight junctions was that ZO-1 antibody is excluded from the leading edge cells, only labelling cell junctions one row behind the leading edge. In addition, the authors showed that Myosin II colocalized with the actin cable in a beaded pattern and was excluded from the anchor points at cell junctions, suggesting that this is really a contractile cable. Danjo and Gipson (1998) were able to demonstrate the functional importance of this actin cable system when they disrupted it reversibly using an E-Cadherin blocking antibody; here the cable falls apart and the leading edge cells begin to extend prominent lamellipodia. Similarly, filopodia extensions have been observed in other systems when the actin cable is not formed, as described above in Drosophila Rho1 mutants (Wood et al., 2002) and also in tissue culture when Rho kinase is inhibited (Russo et al., 2005).

Danjo and Gipson (2002) took a close look at the leading edge of the migrating epithelium in wounded cornea by specifically labeling the margin cells with GFP. The results were quite surprising: after wound healing had proceeded for $18 \mathrm{hrs}$ they found labeled cells many rows back from the leading edge and in various locations within the stratified epithelium. It is difficult to reconcile this with the fact that cells surrounding the wound are never wedged shape, i.e. probably don't pinch off and move backwards within the tissue like in Drosophila(Wood etal., 2002). Is the cable locally disassembled and reassembled? Is it really a continuous contractile cable, or more a tether, holding the cells in place, more important for coordinated movement, rather then cinching the cells together as the term "purse string" implies? Hopefully in vivo live imaging techniques will be developed for this system and provide answers to these questions.

\section{Wound repair activating signals}

One question that remains unanswered from all these studies is of the nature of the signal that induces the formation and contraction of the actin ring. Rosenblatt et al. (2001), suggest that in MDCK epithelia a very early signal derived from the apoptotic pathway (before Caspase activation and any visible sign of apoptosis) induces the formation of the actin ring in the neighbouring cells and the delamination of the dying cells. Ninov etal. (2007) also suggest that an apoptotic signal coming from the Drosophilalarval epidermal cells might be triggering the actomyosin ring contraction in these cells and their consequent delamination. In either case it seems likely that an apoptotic or necrotic signal emanates from a dying cell and induces in its neighbours the formation of a contractile actomyosin cable that is capable of resealing the epithelium.

Also, several studies indicate that the JUN N-terminal kinase (JNK) signalling pathway is an important player in this process, acting downstream of the triggering signal that activates wound closure. Ramet et al. (2002) have shown that puckered (puc), a known target of the JNK signalling pathway, is expressed at the edge of the wound in epithelial cells and that Jun kinase is phosphorylated in wounded epidermal tissues, suggesting that this pathway is activated by a signal produced by an epidermal wound. In flies where JNK signalling is impaired puc expression is no longer induced in wounds and the epithelial cells at the edge of the wound fail to undergo the cell shape changes and do not exhibit protrusive extensions that are characteristic of the repair process (Ramet et al., 2002).

More recent studies using Drosophila larval epidermis (Galko and Krasnow, 2004) and wing imaginal discs, the larval tissues that give rise to wings (Bosch et al., 2005; Mattila et al., 2005), have also shown that JNK signalling is crucial for wound healing in Drosophila. The imaginal discs studies are particularly interesting as the repair mechanisms are very similar to what has been observed in embryos. After wounding the columnar and peripodial epithelia cells in the wing imaginal discs, the wound edge forms a contractile actin cable that starts closing the wound. This is followed by a zipping process achieved through filopodial protrusions from both epithelial margins, knitting the wound edges from proximal to distal areas of the disc. Expression of puc is induced in several rows of cells at the edge of the wound, suggesting that JNK signalling is involved in this process, and consistent with this, mutants for components of the JNK pathway, hemipterous, basketand Dfos, do not repair wounds correctly (Bosch et al., 2005; Mattila et al., 2005). Our own studies in fly embryos have shown that Djun, another JNK signalling component, is also required for embryonic epithelial repair (unpublished observations). This role of JNK signalling in tissue repair seems to be conserved across species. Conditional mutant mice for $c$-jun, in the epidermis, exhibit defects in epidermal wound healing, and mutant keratinocytes extracted from these mice are unable to migrate properly in culture wound healing assays (Li et al., 2003). Also, in monolayer cultures of MDCK cells JNK1 and JNK2 are rapidly and transiently activated upon wounding, and lamellipodial protrusions at the wound edge are blocked in the presence of JNK pathway inhibitors (Altan and Fenteany, 2004). Interestingly, JNK signalling also plays a central role in the regulation of dorsal closure. Mutations in components of the JNK pathway fail to complete this process, lack pucexpression and exhibit cell shape and cytoskeleton defects (reviewed in Jacinto et al., 2002). Interestingly, in flies mutant for the necroticgene, where necrosis is induced in random spots in the epidermis, pucis induced in the tissue surrounding the necrotic regions, suggesting a link between the necrotic signal and the activation of the JNK pathway (Ramet et al., 2002).

Another example of conservation of mechanisms between insect cuticle and mammal skin repair is grainy head. When an epidermal wound is made at late stages of Drosophila embryogenesis, the damaged area can often be spotted in the larvae by the formation of a sclerities, i.e., hard melanized cuticle. Normal cuticle sclerotization is the process by which reactive quinones cross-link protein and chitin polymers to generate the largely impermeable integument of insects. Mace et al. (2005) show that two genes required for normal cuticular sclerotization, a Dopa Decarboxylase and a Tyrosine Hydroxylase, are highly activated in epidermal cells near a wound site in a late stage Drosophila embryo within 30 minutes after injury. Importantly, part of the 
TABLE 1

COMMON FEATURES OF EPITHELIAL RESEALING

\begin{tabular}{|c|c|c|c|c|c|}
\hline & Actomyosin cable & Cytoskeletal protrusions & Cellular junctions & JNK activation & References \\
\hline Drosophila embryo & $\sqrt{ }$ & $L+F$ & A & $\sqrt{ }$ & Wood et al., 2002 \\
\hline Xenopus embryo & $\sqrt{ }$ & L & $?$ & $?$ & Davidson et al., 2002 \\
\hline Chick embryo & $\sqrt{ }$ & No & $A$ & $?$ & Martin and Lewis 1992 Brock et al., 1996 \\
\hline Mouse embryo & $\sqrt{ }$ & No & $?$ & $\sqrt{ }$ & $\begin{array}{l}\text { McCluskey et al. 1993; McCluskey and } \\
\text { Martin 1995; Li et al., } 2003\end{array}$ \\
\hline Caco2 cells & $\sqrt{ }$ & No & $?$ & $?$ & Russo et al., 2005 \\
\hline MDCK cells & $\begin{array}{l}\sqrt{ } \\
\sqrt{ }\end{array}$ & $\begin{array}{l}\mathrm{L} \\
?\end{array}$ & $\stackrel{T}{A+T}$ & $\begin{array}{l}? \\
?\end{array}$ & $\begin{array}{l}\text { Tamada et al., } 2007 \\
\text { Rosenblatt et al., } 2001\end{array}$ \\
\hline Intestine (mouse) & $\sqrt{ }$ & L & $\mathrm{T}$ & $?$ & Watson et al., 2005 \\
\hline Colon (human) & $\sqrt{ }$ & $L+F$ & $\mathrm{~T}$ & $?$ & Bullen et al.,2006 \\
\hline Cornea (mouse) & $\sqrt{ }$ & L & $A$ & $?$ & Danjo and Gipson 1998 \\
\hline Drosophila larvae & No & L & ? & $\sqrt{ }$ & Galko and Krasnow 2004 \\
\hline
\end{tabular}

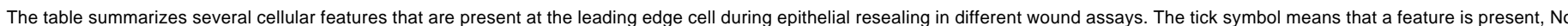

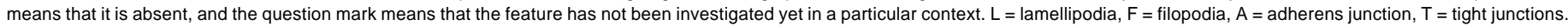

Dopa Decarboxylase promoter fused to GFP was shown to be a useful wound response reporter, activated near the wound site over many cell diameters. This reporter fails to be activated in wounds made in grainy head (grh) mutants. Grh is a major transcription factor expressed in barrier epithelia and necessary for cuticle and head skeleton formation. Consistent with the evolutionary conservation of Grh function, three mouse orthologs of grh are expressed abundantly in developing epithelial cells (Wilanowski et al., 2002; Ting et al., 2003a; Ting et al., 2003b; Kudryavtseva et al., 2003). Interestingly, mice mutant for one of these, Grainy head-like 3, have defects in epidermal protein barrier cross-linking and in epidermal embryonic wound repair (Ting et al., 2005).

In an effort to learn more about the cues that initiate wound repair, Stramer et al. (2008) recently reported a microarray screen comparing the transcriptional profile of wild-type and 'macrophageless' (serpent mutant) Drosophila late embryos in the context of an intact or massively wounded epithelia. This work led to the identification of two genes expressed by haemocytes at the wound site, secreted phospholipase A2 ( $S P L A 2)$ and the antimicrobial peptide drosomycin (Drs), and two genes induced in the wounded epithelium, a lysil oxidase-like gene (CG11335)and the Drosophila orthologue of the growth arrest and DNA damageinducible gene 45 (GADD45).

\section{Biomedical applications}

The knowledge acquired on the studies of actomyosin cable formation and regulation in the different in vivo and in vitro systems has allowed the development of a series of new potential treatments of human diseases. Some of these therapies are based on MLCK and Rho Kinase inhibition and have been shown to have a potential role on the treatment of inflammatory bowel disease and cancer invasiveness. Zolotarevsky et al. (2002) show that TNF- $\alpha$ and IFN- $\gamma$ dependent decrease in the barrier function of the intestine, an early event in inflammatory bowel diseases such as Crohn's disease, can be reverted by inhibiting
MLCK. Myosin light chain phosphorylation has been proposed to lead to actomyosin ring contraction and opening of the tight junction between epithelial cells with the consequent decrease in barrier function of the intestine (Clayburgh et al., 2006). MLCK inhibition causes a decrease in Myosin Light Chain phosphorylation and an increase in transepithelial resistance stopping the cycle of disease progression (Zolotarevsky et al., 2002). The idea that an exaggerated MLCK-mediated contractility of actomyosin leads to leaks in an epithelium due to changes at the level of the cellular junctions is also proposed in the case of inflammatory microvascular permeability (Dull and Garcia, 2002). On the other hand, Takamura et al. (2001) show that Rho Kinase inhibition blocks lamellipodia formation and motility in a human hepatocellular carcinoma cell line. These authors further show in vivo that mice treated with a Rho kinase inhibitor have a decreased incidence of metastatic nodules. In conclusion, the use of MLCK and Rho Kinase inhibitors seems to be a way of restoring epithelial barrier function and decreasing the metastatic potential of cells, respectively, suggesting they might become very useful therapies in the future.

\section{Conclusions and perspectives}

The actin purse string mechanism, while definitely not the only method of epithelial resealing, consistently appears as an important mechanism for healing small to midsized wounds in diverse species at various developmental stages.

The actual wound area reduction and final epithelial resealing though, seems to differ among the various systems discussed. In dorsal closure all cells of the leading edge remain present at that position until the end of the process. The actin cable forms an ellipse, bringing the two opposing sheets close together, which then effectively zipper together from the anterior and posterior canthi via contacting of opposing filopodia (Jacinto et al., 2000). In contrast, in cell culture (Russo et al., 2005) and embryonic wound healing in the Drosophila (Wood et al., 2002) the wound cinches together, in a method conceptually consistent with a 
purse string pulling the leading edge in a coordinated fashion toward one another, resulting in the wound becoming circular and the cells acquiring a wedged shape. As the wound closes some cells pinch back from the leading edge, but remain within the epithelium. The final seamless resealing here is also dependent on filopodia, but the wound can close at a slower pace to the size of 1 cell without them (Wood et al., 2002). In the cornea and possibly other stratified epithelia, some other type of mechanism, which we do not yet understand must be at work. The leading edge cells seem to be completely replaced and largely lost from the epithelium during wound closure (Danjo and Gipson, 2002). This is not entirely surprising, as cornea cells normally slough off and are replaced via stem cell division and cell migration (Charukamnoetkanok, 2006). In oligocellular wounds, such as extrusion of apoptotic cells, each tissue may have developed its subtleties depending on the specific tools available. For instance, tight junctions are very important in the intestine to maintain the permeability barrier, so it is not strange to find ZO-1 as the anchor of the actin cable (Watson et al., 2005; Bullen et al., 2006), while in cornea of the same species where tight junction maintenance may be less crucial, or in Drosophila embryos where tight junctions do not exist, one finds adherens junctions at the cable insertion sites (Wood et al., 2002).

Even with the differences observed (see Table 1), it seems that all epithelial resealing mechanisms described thus far have some basic features in common; in most cases the cells directly bordering the wound are connected by a continuous actomyosin cable, anchored at cell-cell junctions, and/or express cytoskeletal protrusions at their leading edge. Although the cell biology of epithelial resealing is reasonably well understood, there are still many open questions as to the cues that initiate it. Using experimentally amenable systems such as the Drosophila embryo may help us answer these and other open questions in the field.

\section{Acknowledgements}

We thank Leonor Saúde and Soren Prag for critically reading the manuscript and all the lab members for helpful discussions. The authors are supported by Instituto Gulbenkian de Ciência, Fundação para a Ciência e a Tecnologia and EU FPG Network of Excellence Cells into Organs.

\section{References}

ALTAN, Z. M., and FENTEANY, G. (2004). c-Jun N-terminal kinase regulates lamellipodial protrusion and cell sheet migration during epithelial wound closure by a gene expression-independent mechanism. Biochem Biophys Res Commun 322: 56-67.

BEMENT, W. M., FORSCHER, P., and MOOSEKER, M. S. (1993). A novel cytoskeletal structure involved in purse string wound closure and cell polarity maintenance. J Cel/ Bio/121: 565-578.

BOSCH, M., SERRAS, F., MARTIN-BLANCO, E., and BAGUNA, J. (2005). JNK signaling pathway required for wound healing in regenerating Drosophila wing imaginal discs. Dev Bio/280: 73-86.

BROCK, J., MIDWINTER, K., LEWIS, J., and MARTIN, P. (1996). Healing of incisional wounds in the embryonic chick wing bud: characterization of the actin purse-string and demonstration of a requirement for Rho activation. J Cel/ Biol 135: 1097-1107.

BULLEN, T. F., FORREST, S., CAMPBELL, F., DODSON, A. R., HERSHMAN, M. J., PRITCHARD, D. M., TURNER, J. R., MONTROSE, M. H., and WATSON, A. J. (2006). Characterization of epithelial cell shedding from human small intestine. Lab Invest 86: 1052-1063.

CHARUKAMNOETKANOK, P. (2006). Corneal stem cells: bridging the knowledge gap. Semin Ophthalmo/21: 1-7.

CLAYBURGH, D. R., MUSCH, M. W., LEITGES, M., FU, Y. X., and TURNER, J. R. (2006). Coordinated epithelial NHE3 inhibition and barrier dysfunction are required for TNF-mediated diarrhea in vivo. J Clin Invest 116: 2682-2694.

DANJO, Y., and GIPSON, I. K. (2002). Specific transduction of the leading edge cells of migrating epithelia demonstrates that they are replaced during healing. Exp Eye Res 74: 199-204.

DANJO, Y., and GIPSON, I. K. (1998). Actin 'purse string' filaments are anchored by $\mathrm{E}$-cadherin-mediated adherens junctions at the leading edge of the epithelial wound, providing coordinated cell movement. J Cell Sci111: 3323-3332.

DAVIDSON, L. A., EZIN, A. M., and KELLER, R. (2002). Embryonic wound healing by apical contraction and ingression in Xenopus laevis. Cell Motil Cytoskeleton 53: 163-176

DULL, R. O., and GARCIA, J. G. (2002). Leukocyte-induced microvascular permeability: how contractile tweaks lead to leaks. Circ Res 90: 1143-1144.

FRANKE, J. D., MONTAGUE, R. A., and KIEHART, D. P. (2005). Nonmuscle Myosin II Generates Forces that Transmit Tension and Drive Contraction in Multiple Tissues during Dorsal Closure. Curr Bio/15: 2208-2221.

GALKO, M. J., and KRASNOW, M. A. (2004). Cellular and genetic analysis of wound healing in Drosophila larvae. PLOS Biol2: E239.

HARDEN, N. (2002). Signaling pathways directing the movement and fusion of epithelial sheets: lessons from dorsal closure in Drosophila. Differentiation 70 : 181-203.

HARDEN, N., LEE, J., LOH, H. Y., ONG, Y. M., TAN, I., LEUNG, T., MANSER, E. and LIM, L. (1996). A Drosophila homolog of the Rac- and Cdc42-activated serine/threonine kinase PAK is a potential focal adhesion and focal complex protein that colocalizes with dynamic actin structures. Mol Cel/ Bio/16: 18961908.

HUTSON, M. S., TOKUTAKE, Y., CHANG, M. S., BLOOR, J. W., VENAKIDES, S., KIEHART, D. P., and EDWARDS, G. S. (2003). Forces for Morphogenesis Investigated with Laser Microsurgery and Quantitative Modeling. Science

JACINTO, A., WOOD, W., BALAYO, T., TURMAINE, M., MARTINEZ-ARIAS, A., and MARTIN, P. (2000). Dynamic actin-based epithelial adhesion and cell matching during Drosophila dorsal closure. Curr Bio/10: 1420-1426.

JACINTO, A., WOOLNER, S., and MARTIN, P. (2002). Dynamic analysis of dorsal closure in Drosophila: from genetics to cell biology. Dev Cel/3: 9-19.

JANKOVICS, F., and BRUNNER, D. (2006). Transiently Reorganized Microtubules Are Essential for Zippering during Dorsal Closure in Drosophilamelanogaster. Dev Cel/11: 375-385.

KALTSCHMIDT, J. A., LAWRENCE, N., MOREL, V., BALAYO, T., FERNANDEZ, B. G., PELISSIER, A., JACINTO, A., and MARTINEZ ARIAS, A. (2002). Planar polarity and actin dynamics in the epidermis of Drosophila. Nat Cel/ Bio/4: 937 944.

KALTSCHMIDT, J. A., and MARTINEZ ARIAS, A. (2002). A new dawn for an old connection: development meets the cell. Trends Cel/ Biol12: 316-320.

KIEHART, D. P., GALBRAITH, C. G., EDWARDS, K. A., RICKOLL, W. L., and MONTAGUE, R. A. (2000). Multiple forces contribute to cell sheet morphogenesis for dorsal closure in Drosophila. J Cell Bio/149: 471-490.

KUDRYAVTSEVA, E. I., SUGIHARA, T. M., WANG, N., LASSO, R. J., GUDNASON, J. F., LIPKIN, S. M., and ANDERSEN, B. (2003). Identification and characterization of Grainyhead-like epithelial transactivator (GET-1), a novel mammalian Grainyhead-like factor. Dev Dyn 226: 604-617.

LI, G., GUSTAFSON-BROWN, C., HANKS, S. K., NASON, K., ARBEIT, J. M., POGLIANO, K., WISDOM, R. M., and JOHNSON, R. S. (2003). c-Jun is essential for organization of the epidermal leading edge. Dev Ce//4: 865-877.

MACE, K. A., PEARSON, J. C., and MCGINNIS, W. (2005). An epidermal barrier wound repair pathway in Drosophila is mediated by grainy head. Science 308: 381-385.

MARTIN, P., and LEWIS, J. (1992). Actin cables and epidermal movement in embryonic wound healing. Nature 360: 179-183.

MARTIN, P. (1997). Wound healing-aiming for perfect skin regeneration. Science 276: $75-81$.

MARTINEZ-ARIAS, A. (1993). Development and patterning of the larval epidermis of Drosophila. In The development of Drosophila melanogaster, (Bate, A. M.-A. a. M., Ed.), Cold Spring Harbor Laboratory Press, Cold Spring Harbor. pp. 517 - 
607.

MATTILA, J., OMELYANCHUK, L., KYTTALA, S., TURUNEN, H., and NOKKALA, S. (2005). Role of Jun N-terminal Kinase (JNK) signaling in the wound healing and regeneration of a Drosophila melanogaster wing imaginal disc. Int J Dev Bio/49: 391-399.

MCCLUSKEY, J., HOPKINSON-WOOLLEY, J., LUKE, B., and MARTIN, P. (1993). A study of wound healing in the E11.5 mouse embryo by light and electron microscopy. Tissue Cel/25: 173-181.

MCCLUSKEY, J., and MARTIN, P. (1995). Analysis of the tissue movements of embryonic wound healing-Dil studies in the limb bud stage mouse embryo. Dev Bio/ 170: 102-114.

NINOV, N., CHIARELLI, D. A., and MARTIN-BLANCO, E. (2007). Extrinsic and intrinsic mechanisms directing epithelial cell sheet replacement during Drosophila metamorphosis. Development 134: 367-379.

NOBES, C. D., and HALL, A. (1995). Rho, rac, and cdc42 GTPases regulate the assembly of multimolecular focal complexes associated with actin stress fibers, lamellipodia, and filopodia. Ce//81: 53-62.

PERALTA, X. G., TOYAMA, Y., HUTSON, S., MONTAGUE, R., VENAKIDES, S., KIEHART, D. P., and EDWARDS, G. S. (2007). Upregulation of forces and morphogenic asymmetries in dorsal closure during Drosophila development. Biophys J 92: 2583-2596.

POTTEN, C. S., and LOEFFLER, M. (1990). Stem cells: attributes, cycles, spirals, pitfalls and uncertainties. Lessons for and from the crypt. Development 110: 1001-1020

RAICH, W. B., AGBUNAG, C., and HARDIN, J. (1999). Rapid epithelial-sheet sealing in the Caenorhabditis elegans embryo requires cadherin-dependent filopodial priming. Curr Bio/9: 1139-1146.

RAMET, M., LANOT, R., ZACHARY, D., and MANFRUELLI, P. (2002). JNK signaling pathway is required for efficient wound healing in Drosophila. Dev Biol 241: 145-156.

RIDLEY, A. J., and HALL, A. (1992). The small GTP-binding protein rho regulates the assembly of focal adhesions and actin stress fibers in response to growth factors. Cel/70: 389-399.

RIDLEY, A. J., PATERSON, H. F., JOHNSTON, C. L., DIEKMANN, D., and HALL, A. (1992). The small GTP-binding protein rac regulates growth factor-induced membrane ruffling. Ce//70: 401-410.

ROSENBLATT, J., RAFF, M. C., and CRAMER, L. P. (2001). An epithelial cell destined for apoptosis signals its neighbors to extrude it by an actin- and myosin-dependent mechanism. Curr Bio/11: 1847-1857.

RUSSO, J. M., FLORIAN, P., SHEN, L., GRAHAM, W. V., TRETIAKOVA, M. S., GITTER, A. H., MRSNY, R. J., and TURNER, J. R. (2005). Distinct temporalspatial roles for rho kinase and myosin light chain kinase in epithelial pursestring wound closure. Gastroenterology 128: 987-1001.

SINGER, A. J., and CLARK, R. A. (1999). Cutaneous wound healing. NEng/JMed 341: 738-746.

STRAMER, B., WINFIELD, M., SHAW, T., MILLARD, T. H., WOOLNER, S., and
MARTIN, P. (2008). Gene induction following wounding of wild-type versus macrophage-deficient Drosophila embryos. EMBO Rep 9: 465-471.

TAKAMURA, M., SAKAMOTO, M., GENDA, T., ICHIDA, T., ASAKURA, H., and HIROHASHI, S. (2001). Inhibition of intrahepatic metastasis of human hepatocellular carcinoma by Rho-associated protein kinase inhibitor Y-27632. Hepatology 33: 577-581.

TAMADA, M., PEREZ, T. D., NELSON, W. J., and SHEETZ, M. P. (2007). Two distinct modes of myosin assembly and dynamics during epithelial wound closure. J Cell Bio/176: 27-33.

TAPON, N., and HALL, A. (1997). Rho, Rac and Cdc42 GTPases regulate the organization of the actin cytoskeleton. Curr Opin Cel/ Bio/9: 86-92.

TING, S. B., CADDY, J., HISLOP, N., WILANOWSKI, T., AUDEN, A., ZHAO, L. L., ELLIS, S., KAUR, P., UCHIDA, Y., HOLLERAN, W. M., ELIAS, P. M. CUNNINGHAM, J. M., and JANE, S. M. (2005). A homolog of Drosophilagrainy head is essential for epidermal integrity in mice. Science 308: 411-413.

TING, S. B., WILANOWSKI, T., AUDEN, A., HALL, M., VOSS, A. K., THOMAS, T., PAREKH, V., CUNNINGHAM, J. M., and JANE, S. M. (2003a). Inositol- and folate-resistant neural tube defects in mice lacking the epithelial-specific factor Grhl-3. Nat Med9: 1513-1519.

TING, S. B., WILANOWSKI, T., CERRUTI, L., ZHAO, L. L., CUNNINGHAM, J. M. and JANE, S. M. (2003b). The identification and characterization of human Sister-of-Mammalian Grainyhead (SOM) expands the grainyhead-like family of developmental transcription factors. Biochem J 370: 953-962.

VASIOUKHIN, V., BAUER, C., YIN, M., and FUCHS, E. (2000). Directed actin polymerization is the driving force for epithelial cell-cell adhesion. Cel/100:209219.

WATSON, A. J., CHU, S., SIECK, L., GERASIMENKO, O., BULLEN, T., CAMPBELL, F., MCKENNA, M., ROSE, T., and MONTROSE, M. H. (2005). Epithelial barrier function in vivo is sustained despite gaps in epithelial layers. Gastroenterology 129: 902-912.

WIGGLESWORTH, V. B. (1937). Wound Healing in an Insect (Rhodnius Prolixus Hemiptera). J Exp Bio/14: 365-381.

WILANOWSKI, T., TUCKFIELD, A., CERRUTI, L., O'CONNELL, S., SAINT, R., PAREKH, V., TAO, J., CUNNINGHAM, J. M., and JANE, S. M. (2002). A highly conserved novel family of mammalian developmental transcription factors related to Drosophila grainyhead. Mech Dev 114: 37-50.

WOOD, W., JACINTO, A., GROSE, R., WOOLNER, S., GALE, J., WILSON, C., and MARTIN, P. (2002). Wound healing recapitulates morphogenesis in Drosophila embryos. Nat Cel/ Bio/4: 907-912.

YOUNG, P. E., RICHMAN, A. M., KETCHUM, A. S., and KIEHART, D. P. (1993). Morphogenesis in Drosophilarequires nonmuscle myosin heavy chain function. Genes Dev 7: 29-41.

ZOLOTAREVSKY, Y., HECHT, G., KOUTSOURIS, A., GONZALEZ, D. E., QUAN C., TOM, J., MRSNY, R. J., and TURNER, J. R. (2002). A membrane-permeant peptide that inhibits MLC kinase restores barrier function in in vitro models of intestinal disease. Gastroenterology 123: 163-172. 


\section{Further Related Reading, published previously in the Int. J. Dev. Biol.}

See our recent Special Issue Ear Development edited by Fernando Giraldez and Bernd Fritzsch at: http://www.ijdb.ehu.es/web/contents.php?vol=51\&issue=6-7

Stromal-derived factor-1 (SDF-1) expression during early chick development Rizwan Rehimi, Nargis Khalida, Faisal Yusuf, Fangping Dai, Gabriela Morosan-Puopolo and Beate Brand-Saberi Int. J. Dev. Biol. (2008) 52: 87-92

Stem cells for the replacement of inner ear neurons and hair cells Rodrigo Martinez-Monedero and Albert S.B. Edge Int. J. Dev. Biol. (2007) 51: 655-661

Coexpression of Notch3 and Rgs5 in the pericyte-vascular smooth muscle cell axis in response to pulp injury

Henrik Lovschall, Thimios A. Mitsiadis, Knud Poulsen, Kristina H. Jensen and Annette L. Kjeldsen

Int. J. Dev. Biol. (2007) 51: 715-721

Amniotic fluid induces rapid epithelialization in the experimentally ruptured fetal mouse palate - implications for fetal wound healing Toshiya Takigawa and Kohei Shiota

Int. J. Dev. Biol. (2007) 51: 67-77

MP2/4 and BMP5-8 in jellyfish development and transdifferentiation Susanne Reber-Müller, Ruth Streitwolf-Engel, Nathalie Yanze, Volker Schmid, Michael Stierwald, Michael Erb and Katja Seipel

Int. J. Dev. Biol. (2006) 50: 377-384

Geometry and mechanics of teleost gastrulation and the formation of primary embryonic axes

Elena M. Cherdantseva and Vladimir G. Cherdantsev

Int. J. Dev. Biol. (2006) 50: 157-168

Role of Jun N-terminal Kinase (JNK) signaling in the wound healing and regeneration of a Drosophila melanogaster wing imaginal disc

Jaakko Mattila, Leonid Omelyanchuk, Satu Kyttälä, Heikki Turunen and Seppo Nokkala

Int. J. Dev. Biol. (2005) 49: 391-399

Xwig1, a novel putative endoplasmic reticulum protein expressed during epithelial morphogenesis and in response to embryonic wounding. P Klingbeil, G Frazzetto and T Bouwmeester Int. J. Dev. Biol. (2001) 45: 379-385

A laboratory classroom exercise: cell migration in cutaneous wound healing and pigmentary pattern formation in the red-spotted newt. R A Zaccaria

Int. J. Dev. Biol. (1996) 40: 897-899

Mechanism of closure of experimental excision-wounds in the bare upper layer of the chick blastoderm.

$\mathrm{H}$ Bortier, S Vandevelde and L C Vakaet

Int. J. Dev. Biol. (1993) 37: 459-466

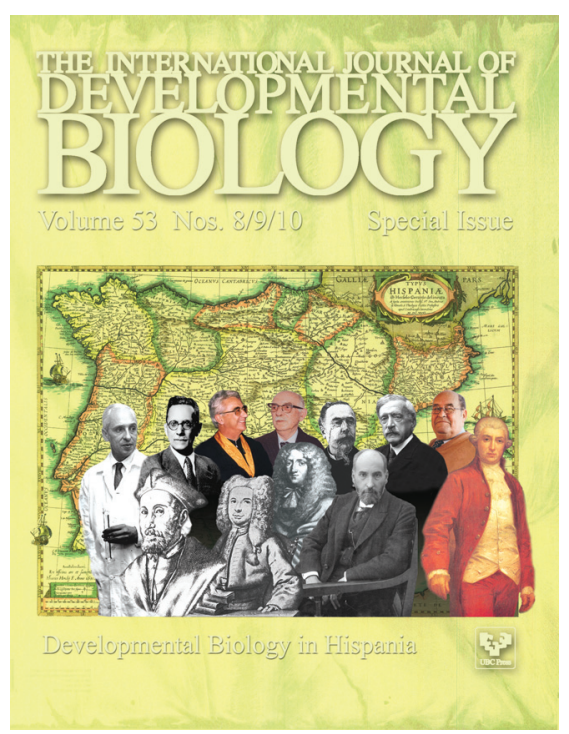

5 yr ISI Impact Factor $(2008)=3.271$

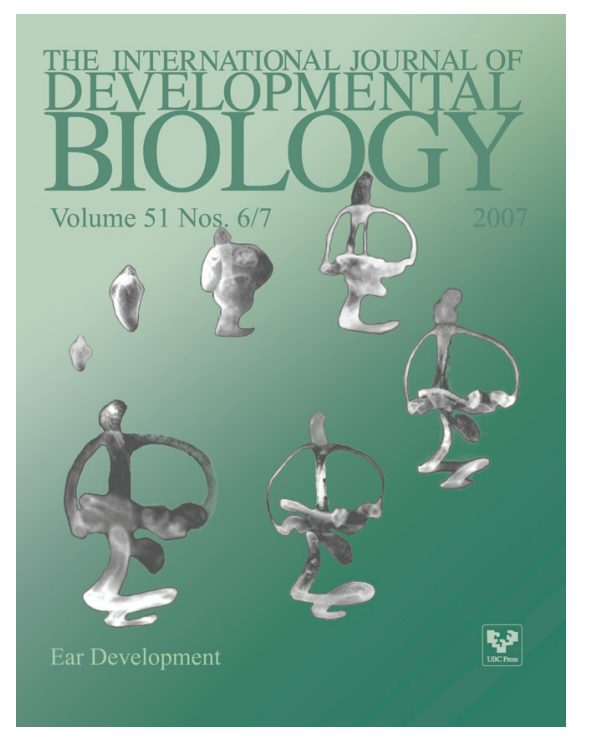

